\title{
A COMPARATIVE STUDY OF HAEMODYNAMIC RESPONSES BETWEEN ENDOTRACHEAL INTUBATION AND LMA INSERTION
}

\author{
Vaidyanathan $R^{1}$, Anand ${ }^{2}$ \\ ${ }^{1}$ Consultant Anaesthesiologist and Intensivist, Department of Anaesthesiology and Critical Care, Cauvery Heart and Speciality Hospital, \\ Mysore. \\ ${ }^{2}$ Consultant Anaesthesiologist, Mysore.
}

\section{ABSTRACT}

$\overline{\text { AIM }}$

To study and compare the haemodynamic response to the insertion of Laryngeal Mask Airway (LMA) with endotracheal intubation in adult patients receiving general anaesthesia.

\section{MATERIAL AND METHODS}

Sixty three patients of either sex between 18-60 years were randomized to two groups. Group I for endotracheal intubation $(n=31)$ and group II for LMA insertion ( $n=32)$. Hemodynamic responses in the form of increased blood pressure or heart rate along with calculated values of Mean Arterial Pressure (MAP) and Rate Pressure Product (RPP) were measured in either group and compared at baseline, post induction, post intubation/insertion and at the end of $1^{\text {st }}, 2^{\text {nd }}, 3^{\text {rd }}$ and $5^{\text {th }}$ minutes.

\section{RESULTS}

Both intubation and LMA insertion were associated with significant increase in Heart Rate (HR), Systolic Blood Pressure (SBP), Diastolic Blood Pressure (DBP), Mean Arterial Pressure (MAP) and Rate Pressure Product (RPP), which returns to baseline by end of two minutes with LMA insertion, whereas it returned to baseline only at the end of five minutes in endotracheal intubation group. Each of the parameters like SBP (Systolic Blood Pressure), DBP (Diastolic Blood Pressure), MAP (Mean Arterial Pressure) and RPP (Rate Pressure Product) showed a significantly less increase with LMA insertion compared to endotracheal intubation; however, though the increase in heart rate was comparatively less in the LMA group, it was statistically not significant.

\section{CONCLUSION}

Significantly less haemodynamic responses (SBP, DBP, MAP, RPP) were seen following LMA insertion compared to direct laryngoscopy in ASA grade I patients. These responses are of no consequence in normal healthy patients; however, the findings especially those on RPP could dictate the routine use of LMA to obtund the pressor response to intubation as a regular feature in patients with risk for perioperative myocardial ischaemia/infarction like those with coronary artery disease and chronic hypertension.

\section{KEYWORDS}

LMA, Pressor Response, Rate Pressure Product (RPP).

HOW TO CITE THIS ARTICLE: Vaidyanathan R, Anand. A comparative study of haemodynamic responses between endotracheal intubation and LMA insertion. J. Evolution Med. Dent. Sci. 2016; 5(11):466-471, DOI: 10.14260/jemds/2016/107

\section{INTRODUCTION}

General Anaesthesia with endotracheal intubation is a time tested procedure practiced all over the world. Direct laryngoscopy and intubation of trachea was considered safe until the hemodynamic response to laryngoscopy and intubation was demonstrated by King et al. in 1951, which is characterized by an increase in heart rate and rise in blood pressure. ${ }^{1}$

This is transitory and returns to baseline and not of much significance in health individuals, but may be hazardous in patients with hypertension or Ischaemic Heart Disease (IHD) and cerebrovascular diseases.

Financial or Other, Competing Interest: None.

Submission 26-12-2015, Peer Review 20-01-2016,

Acceptance 25-01-2016, Published 06-02-2016.

Corresponding Author:

Dr. Vaidyanathan $R$,

Consultant Anaesthesiologist and Intensivist,

Department of Anaesthesia and Critical Care,

Cauvery Heart and Speciality Hospital,

Bannur Road, Teresian Circle, Mysore -11.

E-mail: vaidyadr78@gmail.com

DOI:10.14260/jemds/2016/107
Both pharmacological and non-pharmacological methods have evolved over time to obtund the pressor response to laryngoscopy and intubation. Many methods are described to overcome or obtund this pressor response and use of Laryngeal Mask Airway (LMA) is one such method.

Hence, this prospective study was undertaken with an objective to compare haemodynamic responses of endotracheal intubation to LMA insertion in adult patients.

\section{MATERIALS AND METHODS}

Patients of ASA grade I of either sex aged between 18-60 years with airway grading of Malampatti class I and II undergoing elective gynaecological and surgical procedures were included in the study.

After obtaining institutional ethics committee approval, informed written consent was taken. Routine investigations were done. Patients were randomly allocated into two groups. Method chosen for allocation was simple random sampling. One of the members of the clinical team who was not involved in the study randomly allocated the cases to either of the groups as and when they got enrolled. It was double blinded in the sense neither the allocating person nor the primary 
investigators were aware to which group each case would belong.

Group I for endotracheal intubation (ETT group) (n=31) and

Group II for LMA insertion (LMA group) $(\mathrm{n}=32)$

Patients with IHD, diabetes mellitus, COPD, hypertension and anticipated difficult airway were excluded from the study.

\section{PROTOCOL}

After taking an informed consent, all patients were kept fasting for at least 8 hours prior to surgery. They were briefly counselled regarding the type of the anaesthetic procedure. No premedication was given to any patient.

\section{PROCEDURE}

After the arrival of the patients in the operation theatre, they were placed in the supine position. All the patients were connected to GE Dash $4000^{\mathrm{TM}}$ monitor and heart rate, NIBP, SpO2 and ECG were monitored. Intravenous line was secured if not already present. Baseline heart rates, blood pressure (Systolic and diastolic) were recorded before induction of anaesthesia. Mean arterial pressure and rate pressure product was calculated.

All patients were pre-oxygenated for 3 minutes. Patients were induced with Inj. Thiopentone $5 \mathrm{mg} / \mathrm{kg}$ and Inj. Rocuronium $0.8 \mathrm{mg} / \mathrm{kg}$ was given. Patients' lungs were ventilated with $100 \%$ oxygen with facemask. Blood pressure, heart rate and ECG were recorded in both the groups.

In Group I trachea was intubated with appropriate sized endotracheal tube under direct laryngoscopy using Macintosh laryngoscope. After intubation, bilateral air entry was confirmed and the cuff was inflated. The tube placement was secured with an adhesive tape. In Group II, appropriate sized LMA of LMA Classic TM was inserted blindly without laryngoscopy using standard technique. After insertion, air entry was confirmed on both the lung fields and cuff was inflated until airtight seal was obtained. The LMA in place was secured with adhesive tape.

Once LMA was inserted or trachea intubated, maintenance of anaesthesia was done with $66 \%$ N20 and 02 $33 \%$ and Isoflurane with controlled ventilation using Bain circuit. Injection fentanyl $2 \mathrm{mcg} / \mathrm{kg}$ was given for intraoperative analgesia.

\section{COLLECTION OF DATA}

The study parameters - heart rate, blood pressure - both systolic and diastolic blood pressure were recorded before induction, after induction but before intubation or LMA insertion and at $1^{\text {st }}$ minute, $2^{\text {nd }}$ minute, $3^{\text {rd }}$ minute and $5^{\text {th }}$ minute of intubation or LMA insertion in both Group I (ETT) and Group II (LMA). Mean arterial pressure and rate pressure product were calculated.

Neuromuscular blockade was reversed at the end of the surgery with neostigmine $0.05 \mathrm{mg} / \mathrm{kg}+$ glycopyrrolate $0.2 \mathrm{mg}$ $\mathrm{kg}$. Inj. Diclofenac Sodium at a dose of $1 \mathrm{mg}$ per $\mathrm{kg}$ was given intramuscularly as postoperative analgesic.

Postoperative follow-up was done in all the cases selected in the study. There were no untoward effects during this study like awareness during surgery, postoperative throat pain, etc.

\section{Statistical Analysis}

SPSS for Windows Version 12 was used for analysis. All the values were expressed as mean +/- Standard Deviation (SD). Statistical comparisons were performed by repeated measure of variants followed by student's ' $t$ ' test. A probability value of $\mathrm{p}<0.05$ was regarded as statistically significant.

\section{RESULTS}

This study included 63 patients of either sex admitted for various surgical procedures. They were divided into two groups of 31 and 32 patients each.

Endotracheal intubation - ETT (Group I)

Laryngeal mask airway - LMA (Group II)

All the values were expressed as mean \pm standard deviation. Statistical analysis were performed by repeated measure of variants followed by student's ' $t$ ' test. A probability value of $\mathrm{p}<0.05$ was regarded as statistically significant.

The demographic data of patients is shown in following tables.

\section{Age and Sex Distribution}

\begin{tabular}{|c|c|c|}
\hline $\mathbf{N = 3 1}$ & Mean \pm SD & Range \\
\hline Age & $34.35 \pm 11.56$ & $18-65$ years \\
\hline Body weight & $55.63 \pm 10.85$ & $37-75 \mathrm{~kg}$ \\
\hline Sex ratio & $23.33: 76.67$ & $* * * *$ \\
\hline \multicolumn{3}{|c|}{ Table I: Group I } \\
\hline
\end{tabular}

\begin{tabular}{|c|c|c|}
\hline $\mathbf{N = 3 2}$ & Mean \pm SD & Range \\
\hline Age & $38.16 \pm 11.53$ & $18-65$ years \\
\hline Body weight & $53.97 \pm 9.45$ & $40-85 \mathrm{~kg}$ \\
\hline Sex ratio & $16: 84$ & $* * * *$ \\
\hline \multicolumn{3}{|c|}{ Table II: Group II } \\
\hline
\end{tabular}

\begin{tabular}{|c|c|c|}
\hline Age & Group 1 & Group 2 \\
\hline$<20$ & 4 & 1 \\
\hline s 21-30 & 8 & 11 \\
\hline $31-40$ & 12 & 7 \\
\hline $41-50$ & 5 & 8 \\
\hline $51-60$ & 1 & 5 \\
\hline $61-70$ & 1 & 0 \\
\hline$>70$ & 31 & 32 \\
\hline \multicolumn{2}{|c|}{ Table III: Age distribution } \\
\hline
\end{tabular}

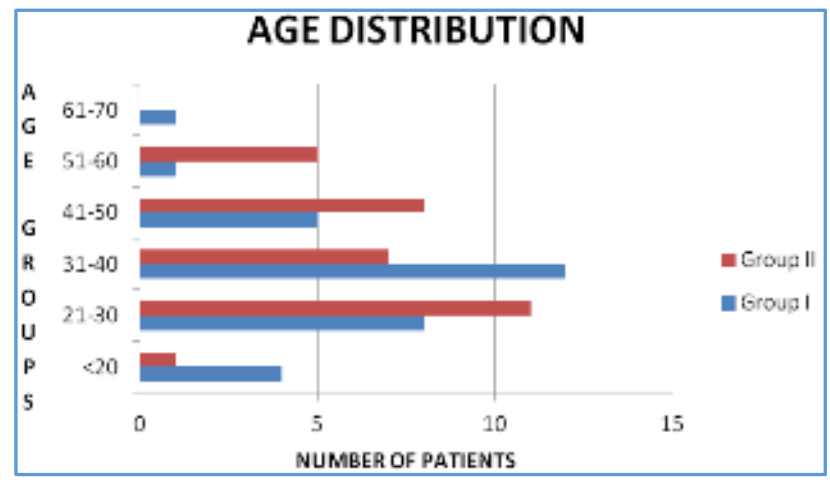

Fig. 1

As can be seen from the tables I-III and fig. 1, the average age of the patients in group I was 34.35 with a Standard Deviation (SD) of 11.56 , while it was 38.16 with a SD of 11.53 in group II. 
The maximum number of patients in group I were seen in the fourth decade of life and in group II it was seen in the third decade of life.

Female preponderance was seen in both groups with a male:female ratio of 23.3:76.67 in group I and 16:84 in group II.

TABLE IV HAEMODYNAMIC CHANGES GROUP I (ETT)
The contingency coefficient revealed a non-significant value on both the occasions, which again confirms the randomness of the sample and the comparability between both the groups with respect to age and sex.

\begin{tabular}{|c|c|c|c|c|c|}
\hline EVENT & $\begin{array}{c}\text { HR } \\
\text { MEAN } \pm \text { SD }\end{array}$ & $\begin{array}{c}\text { SBP } \\
\text { MEAN } \pm \text { SD }\end{array}$ & $\begin{array}{c}\text { DBP } \\
\text { MEAN } \pm \text { SD }\end{array}$ & $\begin{array}{c}\text { MAP } \\
\text { MEAN } \pm \text { SD }\end{array}$ & $\begin{array}{c}\text { RPP } \\
\text { MEAN } \pm \text { SD }\end{array}$ \\
\hline Basal & $82.25 \pm 10.58$ & $130 \pm 13.2$ & $81.06 \pm 6.87$ & $97.57 \pm 8.47$ & $10692.81 \pm 1663.36$ \\
\hline Post induction & $95.2 \pm 16.36$ & $122.88 \pm 13.98$ & $77.63 \pm 10.59$ & $94.01 \pm 10.4$ & $11284.84 \pm 2557.06$ \\
\hline Post insertion & $108.94 \pm 14.56$ & $146.09 \pm 12.38$ & $95.19 \pm 10.3$ & $112.92 \pm 10.01$ & $15807.56 \pm 2618.26$ \\
\hline 1st min & $105.06 \pm 15.04$ & $135.59 \pm 13.42$ & $88.31 \pm 7.95$ & $105.57 \pm 14.15$ & $14061.09 \pm 2334.65$ \\
\hline 2nd min & $98.78 \pm 14.51$ & $126.69 \pm 11.83$ & $82.25 \pm 8.56$ & $97.51 \pm 8.88$ & $12476.25 \pm 1765.06$ \\
\hline 3rd min & $91.34 \pm 12.08$ & $122.31 \pm 9.91$ & $80.75 \pm 7.37$ & $94.7 \pm 7.83$ & $10776.87 \pm 2276.79$ \\
\hline 5th min & $83.16 \pm 12.52$ & $119.06 \pm 10.45$ & $76.75 \pm 9.15$ & $91.63 \pm 8.33$ & $9673.81 \pm 2081.42$ \\
\hline
\end{tabular}

\section{GROUP II (LMA)}

\begin{tabular}{|c|c|c|c|c|c|}
\hline \multirow{2}{*}{ EVENT } & $\begin{array}{c}\text { HR } \\
\text { MEAN } \pm \text { SD }\end{array}$ & $\begin{array}{c}\text { SBP } \\
\text { MEAN } \pm \text { SD }\end{array}$ & $\begin{array}{c}\text { DBP } \\
\text { MEAN } \pm \text { SD }\end{array}$ & $\begin{array}{c}\text { MAP } \\
\text { MEAN } \pm \text { SD }\end{array}$ & $\begin{array}{c}\text { RPP } \\
\text { MEAN } \pm \text { SD }\end{array}$ \\
\hline Basal & $82.06 \pm 12.73$ & $125.42 \pm 10.46$ & $79.48 \pm 6.02$ & $94.79 \pm 6.9$ & $10204.13 \pm 2333.16$ \\
\hline Post induction & $96.48 \pm 14.5$ & $115.68 \pm 15.34$ & $73.81 \pm 10.47$ & $87.14 \pm 10.73$ & $11128.13 \pm 2525.32$ \\
\hline Post intubation & $117.131 \pm 4.39$ & $168.26 \pm 16.5$ & $104.71 \pm 7.49$ & $126.8 \pm 10.5$ & $19213.81 \pm 2933.8$ \\
\hline 1st min & $107.48 \pm 23.26$ & $154.32 \pm 14.86$ & $98.61 \pm 6.9$ & $117.18 \pm 8.76$ & $16830 \pm 2951.39$ \\
\hline 2nd min & $103.97 \pm 17.37$ & $146.39 \pm 17.56$ & $91.10 \pm 6.38$ & $110.64 \pm 15$ & $14608.06 \pm 2534.54$ \\
\hline 3rd min & $99.65 \pm 14.25$ & $127.16 \pm 21.93$ & $83.68 \pm 7.71$ & $99.05 \pm 8.75$ & $12957.81 \pm 2074.12$ \\
\hline 5th min & $85.65 \pm 10.53$ & $124.32 \pm 11.78$ & $79.55 \pm 7.78$ & $94.05 \pm 8.2$ & $10637.35 \pm 1592.24$ \\
\hline
\end{tabular}

\section{Variations in Heart Rate}

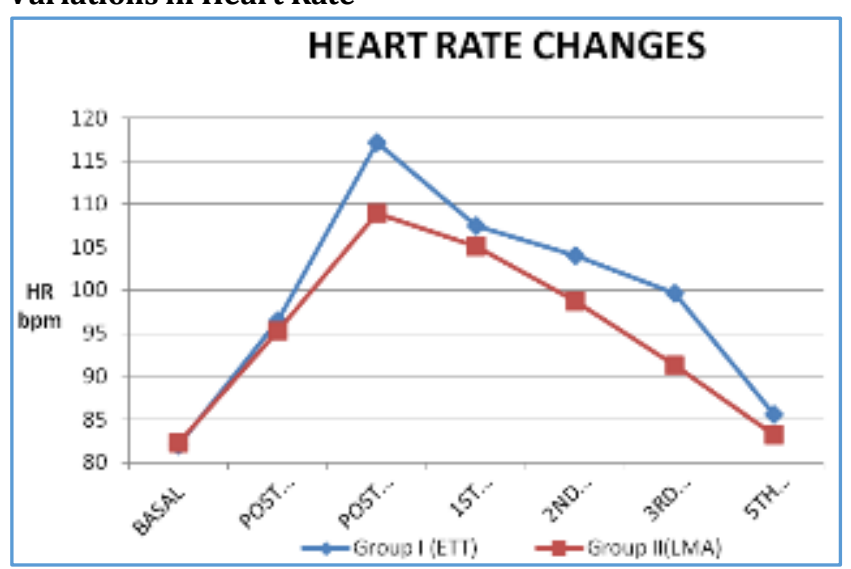

Fig. 2

Significant increase in heart rate was seen in both the groups with the maximum level being attained at the end of intubation or insertion of LMA as seen in Fig. 2.

Group I showed a $47.73 \%$ increase in heart rate from the baseline, which did not return to baseline even by the end of five minutes. [An increase from a mean value of 82.06 beats per minute (bpm) before induction to $117.13 \mathrm{bpm}$ at intubation, which returned to near baseline levels of 85.65 bpm by the end of 5 minutes].

Group II showed a $32.45 \%$ increase in heart rate, which returned to baseline by 5 minutes (An increase from a mean value of $82.25 \mathrm{bpm}$ at preinduction peaking to a level of 108.94 bpm at LMA insertion and returning to basal levels of 83.16 bpm by the end of 5 minutes).

However, when changes in heart rate with respect to the two groups were considered, a non-significant interaction $(p=0.190)$ was seen, which reveals that the difference was statistically not significant and the pattern of change was similar in both the groups.

\section{Variations in Systolic Blood Pressure (SBP)}

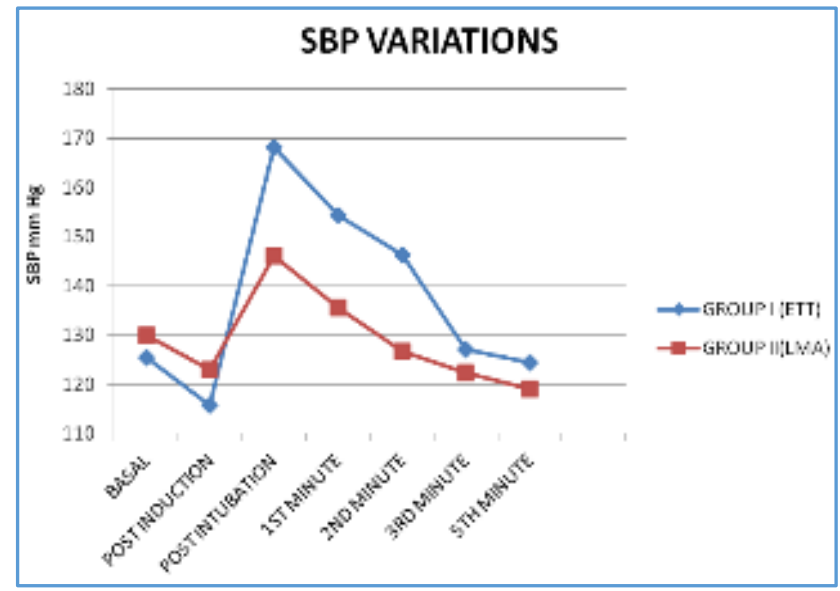

Fig. 3

Fig. 3 represents the significant increase in Systolic Blood Pressure (SBP) noticed in both the groups, which again peaked at the end of intubation or insertion of LMA. 
In group I, the SBP increased from a mean value of $125.42 \mathrm{mmHg}$ before induction to a peak value of $168.26 \mathrm{mmHg}$ at the end of intubation with an increase of $34.17 \%$ from the baseline. This increase in the SBP returned to the baseline values of $124.32 \mathrm{mmHg}$ by the end of five minutes.

In group II, the SBP increased from a mean value of $130 \mathrm{mmHg}$ before induction to a peak value of $146.09 \mathrm{mmHg}$ at the end of insertion of LMA, with an increase of $12.37 \%$ from the baseline value. This increase in SBP returned to less than baseline values of 126.69 by the end of 2 minutes.

The difference was statistically significant with a $\mathrm{p}$ value of $0.002(p=0.002)$.

\section{Variations in Diastolic Blood Pressure (DBP)}

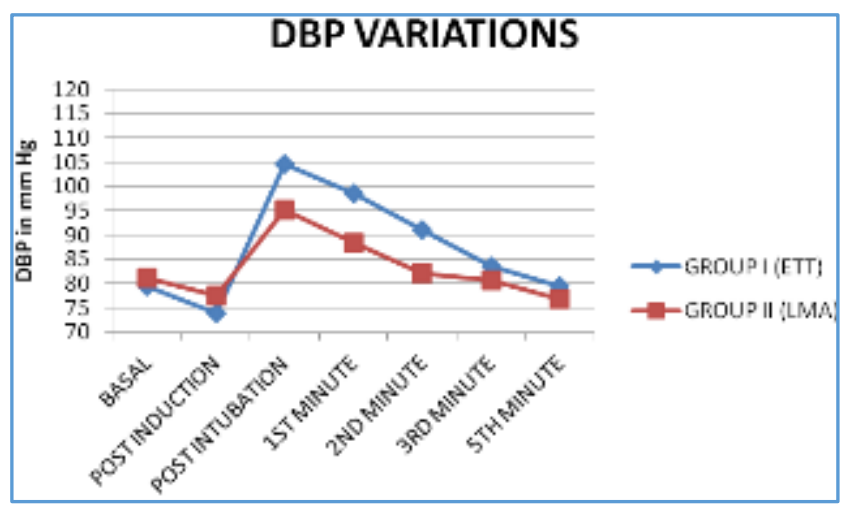

Fig. 4

The DBP showed similar changes in both the groups as shown in Fig. 4. Group I showed a maximum increase of $31.78 \%$ from the baseline to the end of intubation from a mean value of $79.48 \mathrm{mmHg}$ before induction to $104.71 \mathrm{mmHg}$ at the end of intubation and returning to basal levels of $79.55 \mathrm{mmHg}$ by the end of 5 minutes.

Group II showed an increase of $17.38 \%$ from the baseline to the end of placement of the LMA, an increase from a mean value of $81.06 \mathrm{mmHg}$ at baseline to $85.19 \mathrm{mmHg}$ at the point of insertion of LMA. It returned to the baseline values of $82.25 \mathrm{mmHg}$ by the end of 2 minutes.
The difference was statistically significant with a $\mathrm{p}$ value of 0.004 .

\section{Variations in Mean Arterial Pressure (MAP)}

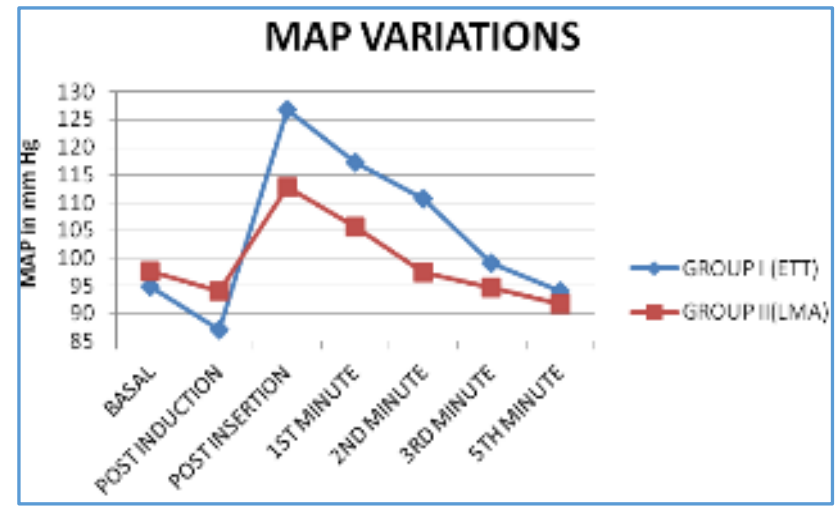

Fig. 5

Group I showed an increase from a mean value of 94.79 at baseline to 126.8 at the end of intubation, about $34.22 \%$ increase from baseline levels of 94.05 by the end of five minutes (Fig. 5).

Group II showed an increase from a mean value of 97.57 prior to induction to a peak value of 112.92 at the end of LMA insertion with an increase of $16.43 \%$ from baseline. This rise returned to baseline values of 97.51 by the end of 2 minutes.

This difference was statistically significant with a $\mathrm{p}$ value of $0.003(\mathrm{p}=0.003)$.

\section{Variations in Rate Pressure Product (RPP)}

As seen in Fig. 6, Group I showed an $88 \%$ increase from baseline values by the end of intubation, an increase from a mean value of 10204.13 before intubation to a peak value of 19213.81. This rise did not come down to the basal levels even at the end of five minutes, which was 10637.05 even at the end of 5 minutes.

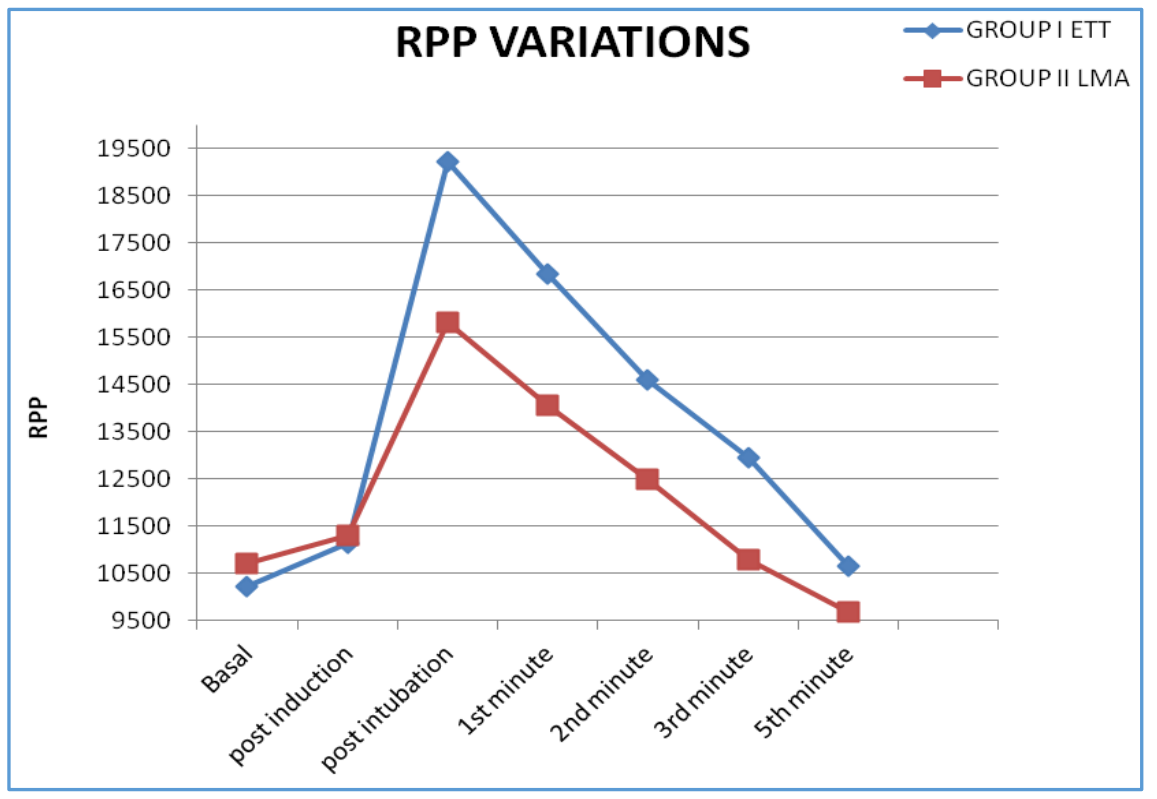

Fig. 6 
Group II showed an increase of $47.78 \%$ from basal values to the end of LMA insertion, an increase from a mean value of 10692.81 before induction to a peak value of 15801.56 when the placement of LMA was achieved. This rise however came back to the basal levels of 10776.87 by the end of 3 minutes.

This difference was again statistically significant with a $p$ value of $0.001(p=0.001)$. This mean value of the Rate Pressure Product (RPP) was well below the critical point of 20000 in both the groups.

\section{DISCUSSION}

The usual circulatory response of tachycardia and rise in blood pressure to intubation are interpreted as being the result of reflex sympathoadrenal stimulation.

Subsequent to the introduction of LMA into the clinical practice by Brain and Collegues.2,3 in 1981, Braude et al. 4 observed for the first time that the insertion of LMA might be associated with a lesser haemodynamic response compared to endotracheal intubation in 1989.

Wilson et $a .^{5}$ found in their study of 40 patients an increase of heart rate of $26.6 \%$ in intubation group compared to a $25.7 \%$ increase in LMA group from the basal level. They also noticed a similar increase in systolic blood pressure after intubation (17.1\%) compared to LMA insertion (8.6\%). Similar changes were seen in the diastolic blood pressure (max mean rise of $26.86 \%$ ) in the ETT group compared to the LMA group. (Max mean increase of $11.8 \%$ ).

In the present study of 63 patients, a significant increase in heart rate was seen in both the groups. While group I (ETT) showed a $47.73 \%$ increase from baseline, group II showed a $32.45 \%$ increase in heart rate from baseline. During intubation or LMA insertion the difference in heart rate when compared between the 2 groups was statistically not significant. However, there was a significant fall in heart rate from the second minute onwards in LMA group in contrast to the ETT group, in which it remained elevated up to the end of third minute and started to fall later. These findings are similar to those noticed by Wilson. ${ }^{5}$ and Colleagues.

Similarly, there was a $34.17 \%$ increase in systolic blood pressure from baseline in the ETT group compared to a $12.37 \%$ increase seen in LMA group, which was statistically significant $(\mathrm{p}=0.02)$. It took 5 minutes for the SBP to return to preinduction levels in case of endotracheal intubation, while it reached basal levels within 2 minutes following LMA insertion. Similar variations were noticed with regard to Diastolic Blood Pressure (DBP). There was a $31.78 \%$ increase in DBP from baseline following intubation compared to a $17.38 \%$ increase with LMA insertion, which was statistically significant $(p=0.004)$. Again 5 minutes had elapsed before the DBP could reach basal levels in ETT group, whereas it reached baseline within 2 minutes in LMA group.

These findings are similar to what has been observed earlier by Kaul et al.6, Bhukari et al. ${ }^{7}$, Montazari et al. ${ }^{8}$ and $\mathrm{M}$ Tabari et al. ${ }^{9}$

The reasons for such an attenuated increase in blood pressure and an almost identical increase in heart rate following the use of LMA in comparison to endotracheal intubation have been intensely debated. 4,5

It has been postulated by Shribman et al. 10 that the heart rate increase after intubation may be a response to an imbalance between the vagal and cardiac accelerator fibres. The sustained increase in heart rate even after 5 minutes could be explained by the continued stimulation of the tracheal tube. ${ }^{4}$

In another study by Venkatesh and Umamaheshwara Rao. ${ }^{10}$ they suppressed both the stimuli independently - 4\% lignocaine spray to block vagal stimulation of larynx and glossopharyngeal nerve block to obtund the response to direct laryngoscopy. They had grouped their patients into 6 groups Group I - Direct laryngoscopy without sensory block (DL)

Group II - Fibreoptic intubation without block (FI)

Group III- Direct laryngoscopic intubation after glossopharyngeal block (DL-GN)

Group IV- Fibreoptic intubation after 4\% lignocaine spray (FI-LS)

Group V - Direct laryngoscopic intubation after 4\% lignocaine spray and glossopharyngeal nerve block (DL-GNB+LS)

Group VI - Direct laryngoscopic intubation after 4\% lignocaine spray (DL-LS)

They found that the groups I, II, III and IV, i.e. DL, FI, DL+GNB and DL had significant tachycardia $(\mathrm{p}<0.05)$ and increase in SBP, DBP, MAP and RPP following tracheal intubation indicating presence of at least one stimuli.

Groups V and VI, viz. FI-LS and DL-LS+GNB had no tachycardic or hypertensive response or increase in RPP suggesting the absence of both laryngoscopy and intubation stimuli.

They concluded that both laryngoscopy and intubation are powerful stimuli for hypertensive and tachycardic response following intubation and are best attenuated by blocking both the stimuli.

In this study there was a $34.22 \%$ increase in MAP in the ETT group from baseline following intubation, which returned to baseline in 5 minutes, while in LMA group there was $16.48 \%$ increase in MAP from baseline following LMA insertion, which returned to baseline in 2 minutes. These results are similar to those observed by Kaul et al. ${ }^{6}$ and Chawla et al.11

Heart rate is a major determinant of myocardial oxygen consumption and tachycardia is poorly tolerated in the postop period in patients with IHD. Levels of Rate Pressure Product (RPP) in excess of 20000 are commonly associated with angina and myocardial ischemia. ${ }^{12,13}$

In this study, mean RPP after intubation in the ETT group was $19213.81 \pm 2933.8$ and that after LMA insertion was 15801.56 \pm 2618.26 . Fourteen patients in group I had a RPP $>20000$, while no patient in group II had a RPP $>20000$. Three patients in group I had dysrhythmias during intubation and all of them had a RPP>20000. However, none of the patients in this group had any ischaemic changes and none of the patients in the LMA group had any ECG changes during LMA insertion.

These findings are similar to what has been described in few earlier studies. ${ }^{13,14,15}$

\section{CONCLUSION}

To conclude, both intubation and LMA insertion was followed by a significant increase in HR, SBP, DBP, MAP and RPP in this study which returned to baseline by the end of 5 minutes in ETT group and by the end of 2 minutes in LMA group. These changes may not be of much significance in healthy individuals. All these parameters showed a significantly lesser increase with LMA compared to endotracheal intubation except for heart rate, which was statistically not significant. 
Fourteen patients in ETT group had a RPP $>20000$ and 3 of them had dysrhythmias. None of the patients in the LMA group had a RPP $>20000$.

Thus it can be concluded that the use of LMA achieves much higher cardiovascular stability and that the occurrence of dysrhythmias decreased with the use of LMA.

It can thus be re-postulated based on this study and available sparse evidence that routine use of LMA tend to decrease the catecholamine surge and pressor response in both normal healthy individuals and also in patients with hypertension and IHD in whom it may have more deleterious effects.

In a recent study by Kiran et al. ${ }^{16}$ comprising 60 hypertensive patients randomized to 2 groups of endotracheal intubation and LMA insertion, they found results very similar to our study suggesting a role for LMA in attenuating the pressor response as a routine in hypertensive patients.

Bennet et al. ${ }^{14}$ and Kahl et al.15 in two separate small studies on patients with IHD undergoing Coronary Artery Bypass Grafting (CABG) also separately demonstrated a much attenuated response of HR, SBP, DBP, MAP and RPP with the use of LMA. Further Kahl and Colleagues had also observed a higher incidence of ischaemia (5 to 2) with the use of laryngoscopy compared to LMA.

However, a large study comprising all age groups may be required to evaluate the increase in RPP over 20000 in relation to its prediction of intra- and post-operative myocardial ischaemia/infarction in not just IHD or hypertensive patients, but also in routine normotensives. This could dictate the routine use of LMA to obtund the pressor response to intubation as a regular feature.

\section{LIMITATIONS}

1. As this study was carried out in ASA grade I patients undergoing elective gynaecological and surgical procedures, invasive monitors to continuously monitor the haemodynamic changes were not justified.

2. Plasma catecholamine levels were not measured in any of the patients.

3. Hypertensive and IHD patients were not considered in this study in whom the demonstration of the attenuated pressor response might be really beneficial.

\section{REFERENCES}

1. King BD, Harris LC, Greefenstein FE, et al. Reflex circulatory responses to direct laryngoscopy and tracheal intubation performed during general anaesthesia. Anaesthesiology 1951;12:556.

2. Keerthi Kumar S, Lt. Col. Rama Naik. The history of evolution of LMA. Ind J Anesth 1999;43:22

3. Takashi Asai, Stephen Morris. The laryngeal mask airway; its features effects and role. Canadian J Anaesth 1994;41(10):930-960.

4. Braude N, Clements EAF, Hodges UM, et al. The pressor response and laryngeal mask insertion. A comparison with tracheal intubation. Anaesthesia 1989;44;551-4.
5. Wilson IG, Fell D, SL Robinson, et al. Cardiovascular responses to insertion of laryngeal mask. Anaesthesia 1992;47:30-302.

6. Tej Kaul, Veena Valecha, Suneet Kathuria, et al. Catecholamine response to endotracheal intubation and laryngeal mask airway insertion. Ind J Anesth 1999;43:30-32.

7. Syed Altaf Bukhari, Imtiaz Naqash, Javed Zargar, et al. Pressor responses and intraocular pressure changes following insertion of laryngeal mask airway: comparison with tracheal tube insertion. Ind J Anaesth 2003;47(6):473-475.

8. Montazari K, Naghibi KH and Hashemi. Comparison of haemodynamic changes after insertion of LMA, facemask and endotracheal intubation. Acta Medica Iranica. 2004;42(6):437-440.

9. Masoomeh Tabari, Mohammad Alipour, Mahdi Ahmadi. Hemodynamic changes occurring with tracheal intubation by direct laryngoscopy compared with intubating laryngeal mask airway in adults: a randomized comparison trial. Egyptian Journal of Anaesthesia (2013) 29, 103-107.

10. Venkatesh HK, Umamaheshwara Rao GS. Optimal combination of laryngoscopy and airway anaesthesia to minimize cardiovascular response to tracheal intubation.

J Anaesth Clin Pharmacol 2004;20(4):379-386.

11. Chawla R, Kumar M, Kundra P, et al. A comparative study of intraocular pressure changes with laryngeal mask airway and tracheal tube. J Anaesth Clin Pharmacol 1993;9(4):265-267.

12. Yoshitaka Fuji, Hidenari Toyooka, Hiroyoshi Tanaka. Circulatory responses to laryngeal mask airway insertion or tracheal intubation in normotensive and hypertensive patients. Canadian J Anaesth 1995;42(1):32-36.

13. Ansari M1, Javadi H, Pourbehi M, et al. The association of rate pressure product (RPP) and myocardial perfusion imaging (MPI) findings: a preliminary study. Perfusion 2012 May;27(3):207-13.

14. Bennet SR, Grace D, Grifffin SC, et al. Cardiovascular changes with the laryngeal mask airway in cardiac anaesthesia. Br J Anaesth 2004;92(6):885-887.

15. Kahl M, Leopald HJ, Eberhart, et al. Stress response to tracheal intubation in patients undergoing coronary artery surgery. Direct laryngoscopy versus an intubating laryngeal mask airway. Journal of cardiothoracic and vascular anaesthesia. 2004;18:275-280.

16. Kiran, Sandhya Balleda, Anjani Sravanthi Kotturi, et al. Comparative study of haemodynamic response to laryngeal mask airway versus endotracheal tube in hypertensive patients. Asian Pacific Journal of health sciences, 2015;2(1):10-17. 